\title{
The Adam Smith Problem: Integrating Self-Interest with Justice in Liberal Society
}

Zachary Breininger* and John Carson, $\mathrm{PhD} \dagger$

University of Michigan Research Scholars

*To whom correspondence should be addressed: zpbrei@umich.edu

†jscarson@umich.edu

Adam Smith is best known for his economic theories that extoll the free market and individual self-interest. These ideas are the focus of Smith's second book, The Wealth of Nations. However, Smith also made large contributions to the fields of ethics and moral philosophy. Nearly 20 years prior to the publication of The Wealth of Nations, Smith first became a renowned moral philosopher when he published The Theory of Moral Sentiments. In The Theory of Moral Sentiments, Smith outlines the nature of morality. This morality, for Smith, places an emphasis upon sympathy and compassion, which are felt by imagining the plight of others through the impartial spectator. This impartial spectator is a mode of thinking that allows for one to adjudge the actions of others in relation to society's general attitudes toward that said action. Despite Smith's consummate rumination in both books, there seems to be a disconnect between Smith's moral philosophy, found within The Theory of Moral Sentiments, and his economic philosophy, found within The Wealth of Nations. How can Smith eulogize compassion and fellow feeling in one writing, while also holding that self-interest is necessary for the advancement of society in another? This disconnect is known as the Adam Smith Problem. The purpose of this project is to acknowledge the existence of The Adam Smith Problem by seeing it not as an attempt to undermine Smith's intellectual continuity, but as a challenge to reconcile the self-interested nature of humanity with higher moral standards accomplished through compassion. This reconciliation is accomplished through the notion of a liberal society in which an individual is both free to do anything that does not harm another and can expect society to maintain a higher set of moral standards through a justice system. Both wealth proliferation through self-interest and the upholding of higher values through compassion are predicates of this liberal society: the culmination of Smith's philosophy.

\section{Introduction}

Adam Smith's contributions to human thought span countless fields, ideologies, and eras. A plethora of intellectuals as diverse as Karl Marx, Friedrich Hayek, and Noam Chomsky have been influenced by Smith. Adam Smith may be best known for his seminal work originally published in 1776, The Wealth of Nations, in which he attempts to understand the economic processes that he experienced whilst also making arguments for what would become a market economy. The Wealth of Nations, however, is only one of the two books produced by Adam Smith. The other work was The Theory of Moral Sentiments, published in 1759. The primary focus of the Theory of Moral Sentiments is to understand the moral underpinnings of human behavior. For Smith, virtues and the means by which society manifests these virtues is the main point of the book.

Smith's two seminal works, The Theory of Moral Sentiments and The Wealth of Nations, both attempt to outline the nature of human behavior. However, they approach the issue of human behavior from different vantage points. A supposed problem that exists is a disparity in how the two works address human behavior that some have concluded render the works at odds with one another and thus make a direct connection between the works impossible. In The Theory of Moral Sentiments, mankind is driven by morality, whereas in The Wealth 
of Nation, mankind is driven by self-interest. However, this view and most previous scholarship on the topic does not attempt to view both works as connected in any way, nor have previous scholars attempted to find linkages in the general societal framework put forth by Smith. They view the works as wholly independent, even though they were produced by the same thinker. This article attempts to highlight connecting themes and conceptions found in both works that suggest that the works are, in fact, compatible. Furthermore, it will be argued that once one has viewed the works as part of a coherent, overarching philosophical corpus, Smith comes to create the framework of a liberal society in which both self-interest and morality exist in free trade and justice. This article is divided into four main sections: What is the Adam Smith Problem, Smith's The Theory of Moral Sentiments, Smith's Conception of Trade and its Connection to Morality, and The Liberal Society of Smith. Most previous scholarship on the matter attempts to rectify the Adam Smith Problem by viewing the two aforementioned works in isolation. The Theory of Moral Sentiments and The Wealth of Nations are linked in Smith's idea that justice serves as the predicate of free trade. A society in which this is manifested is, as Smith and scholars have come to understand it, called a liberal society. It is liberal in the sense that one is free to do whatever is in his or her self-interest that does not violate the freedoms of others and the basic rules of morality in a society. Smith's teleological progression that envisions society as progressing towards this liberal ideal, using the concept of trade as the main argumentative mechanism, is outlined. This teleology is seldom discussed in previous scholarship, especially since Smith was writing in an age in which the concepts of liberalism and free trade were on the rise as was the belief that society was slowly being perfected. The year that The Wealth of Nations was published also happens to be the year the United States declared independence from England, an event heralded as a triumph of liberalism over monarchism. Thus, Smith's conceptions of liberty and free markets are at the forefront of classical-liberal thought as it is known today. In all, solving the Adam Smith Problem provides an opportunity to link two of history's most important works, The Theory of Moral Sentiments and The Wealth of Nations, in an attempt to outline the very crux of Adam Smith's philosophy: the outlines of a liberal society.

\section{Defining the Problem}

James R. Otteson in "The Recurring Adam Smith Problem" outlines this problem in full.
First, in TMS Smith presents a picture of human virtue that comprises a balance of four separate virtues, a picture that is absent from WN. Second, in WN Smith on more than one occasion explicitly states that men are driven by the universal desire to better their own condition, a desire that apparently issues from self-interest, and Smith treats this universal desire as if it were the sole motive to act that men naturally have. ${ }^{1}$

Otteson's analysis of Smith's work offers a challenge to the philosophical community to reconcile the rift in the language between the two pieces. Although Otteson is undoubtedly one of the foremost Adam Smith scholars, his challenge to solve the Adam Smith Problem is rather open-ended. Otteson puts forth the following possible solution:

Nevertheless, it may be the case that there are ways to mitigate the Adam Smith Problem. I think that a single, implicit methodological model for understanding the growth and maintenance of human institutions is at work in both TMS and WN which, if true, would unite the two books on a deep level. Simply stated, this model is that of a market in which free exchanges among people pursuing their own interests give rise over time to an unintended system of order. I think Smith sees this model at work in all large scale institutions, including in particular common standards of morality and economic marketplaces. If this model proves coherent and capable of actually explaining the institutions it is meant to explain, it might also provide a first step toward solving the general problem of morality and markets. ${ }^{2}$

The challenge to resolve the Adam Smith Problem, therefore, must not be a rewording of Smith, nor an attempt at dismissing one aspect of Smith's philosophy on account of some supposed inconsistency. This, in effect, leads to many of the unsatisfactory resolutions to the Adam Smith Problem. For example, previously proposed solutions to the Adam Smith Problem have primarily focused on the scope of both works. Scholars, like Richard Teichgraeber III, have proposed that The Theory of Moral Sentiments and The Wealth of Nations pertain to entirely different aspects of the human experience. They contend that The Theory of Moral Sentiments discusses the morality entirely within the aethereal realm: in terms of what ought to be; whereas, The Wealth of Nations outlines proper conduct within the economic realm: what is actual. Unfortunately for this view, there is a considerable amount 
of overlap. Take, for example, what Smith has to say about trade. Is trade not an everyday occurrence? Smith himself acknowledged the overlap. "Is it not from the benevolence of the butcher, the brewer, or the baker, that we expect our dinner but from their regard to their own interest." ${ }^{3}$ In this oft-quoted passage from The Wealth of Nations, one can see the undeniable link between morality and economics. Thus, the entire concept of trade is predicated on mutual selfinterest.

Considering this, the supposition that Adam Smith's language became more focused on self-interest in The Wealth of Nations, as opposed to the sympathy and beneficence in The Theory of Moral Sentiments, is far too focused upon the tone and language of the works. Rather than viewing the Adam Smith Problem in terms of language, one must analyze the problem in terms of trade. Trade is imbued with both economic practice and moral theory; it is the meeting place between humanity's sentiments and bank account. Certainly, if one is to analyze The Theory of Moral Sentiments in isolation, one will find an overarching emphasis upon the notions of virtue and greater morality. Many of Smith's overarching arguments about economic progress are dependent upon his postulations regarding a moral philosophy found within The Theory of Moral Sentiments.

\section{Smith's Theory of Moral Sentiments}

Virtue and the means by which society manifests these virtues is the main point of concern in The Theory of Moral Sentiments. Central to manifesting virtue in society is the impartial spectator.

Impartial spectator; that allows no word or gesture to escape it that wouldn't be dictated by this more equitable sentiment [i.e. by the feelings of an impartial spectator]; that never, even in thought, attempts any greater vengeance or wants to inflict any greater punishment than what every person who isn't directly involved would be happy to see inflicted. ${ }^{4}$

This impartial spectator is the ideal judge, slow to resentment and eager to promote happiness. It is what allows human beings to view the world through the lens of morality. One must not take the impartial spectator to mean an actual being in which virtue and vice are determined. Such a view would make the impartial spectator out to be God. This, however, is not the case. Rather, the impartial spectator is a theoretical frame of mind in which one can place themselves in order to discern the actions of one another and themselves. This impartial spectator frame of mind is primarily conducted through sympathy.

The Theory of Moral Sentiments analyzes the nature of sympathy and its relationship with the formulation of human morality. "Sympathy . . . can . . . denote our fellow-feeling with any passion whatever."' In labeling sympathy this way, Smith makes the argument that sympathy can be used in a variety of different contexts in combination with a variety of different emotions. Sympathy can be used positively when in combination with pity and compassion. Likewise, sympathy can be directed towards even the vilest acts, such as sympathizing with a murderer in his motives. Within this duality of sympathy, the commonality between the most positive and negative implementations of sympathy is the spectator and her imagination.

Sympathy alone does not allow the impartial spectator to understand the conditions of others. The impartial spectator is not the amalgamation of various instances of emotion. Rather, it must have the ability to peer into the various circumstances and intentions of others. Imagination is the way in which this is achieved. Smith notes that "We have no immediate experience of what other men feel; thus, the only way we can get an idea of what someone else is feeling is by thinking about what we would feel if we were in his situation ... Our imagination comes into this, but only by representing to us the feelings we would have if, etc." 4 Smith is quick to note the importance of the individual being able to have "fellow-feeling" with the person upon whom sympathy is being bestowed. Like sympathy, the ability of the spectator to show either positive (compassion and pity) or negative (anger and resentment) forms of pity is dependent upon the position of the spectator and her imagination. Imagination in the mind of the spectator permits us to put "ourselves in their situation - inserting our living souls into their dead bodies (so to speak) and conceiving what our emotions would be in that situation." "This is a valuable tool that nature, according to Smith, has allocated man for the sake of formulating morality. Nature, however, is not the product of itself. In Smith's mind, it must have been created. A deity holds a special place within morality for Smith. This is primarily manifested through natural law.

Morality, for Smith, is originated by the divine and given to humanity in the form of natural law. "The happiness of mankind and of all other rational creatures seems to have been the original purpose of the Author of nature when he brought them into existence ... So we are naturally encouraged to hope for his extraordinary favor and reward in the 
one case, and to fear his vengeance and punishment in the other." Here, Smith links a prevailing sense of right and wrong, which is at the core of his moral philosophy, to a divine Author of the universe. This Author's will coincides with another tenant of Smith's moral philosophy: merit and demerit. "When the general rules that determine the merit and demerit of actions come in this way to be regarded as the laws of an all-powerful Being who watches over our conduct and who will in a life to come reward the observance of them and punish the breach of them, this endows them with a new sacredness." ${ }^{4}$

Indeed, Smith's moral philosophy is predicated upon the existence of a divine natural law that manifests itself in either the issuance of merit or demerit by the civil authority, acting in accordance with natural law. For Smith, this proper issuance of merit and demerit is the essence of justice:

The very existence of society requires that underserved and unprovoked malice should be restrained by proper punishments, and thus that inflicting those punishments should be regarded as a proper and laudable action. And men are naturally endowed with a desire for the welfare and preservation of society; but the Author of nature hasn't left it to men to use their reason to work out what kinds and levels of punishment are right for this purpose; rather, he has endowed men with an immediate and instinctive approval of just precisely the kind and level of punishment that is most proper to attain it. ${ }^{4}$

Therefore, mankind's faculties, which include the impartial spectator, allow us to ascertain what constitutes the right course of action.

Despite the universal nature of natural law, Smith contends that the multiplicity found within societies and cultures can be explained through a rational analysis of the implementation of the law. Each society is an instantiation of the natural law which occurs in an ongoing effort to reach the optimal society: one in which natural law is the rule of law in the society. This multiplicity and the proximity to the divine are the foundation of societal advancement that allows for some of the market forces that are to be described further on.

Although Smith gives no indication of how natural law ought to be implemented, he puts forth a teleological explanation for the precipitous advance of society away from barbarity towards, in his mind, the law of the Divine Author. Yet, how does this outlining of the moral system in any way comport with the idea that self-interest advances society? After all, would not the impartial spectator look unfavorably upon greed? Does not the divine law which can be interacted with through the impartial spectator show disapprobation towards? These questions get to the heart of the Adam Smith Problem. How can a system that supports greed and selfinterest be grounded within a moral framework? To answer this, one must investigate trade: the meeting place for both self-interest and sympathy.

\section{Smith's Conception of Trade and its Connection to Morality}

At the heart of the Smithian notion of trade is the market model, predicated upon the division of labor. Smith notes:

Among men, on the contrary, the most dissimilar geniuses are of use to one another; the different produces of their respective talents, by the general disposition to truck, barter, and exchange, being brought, as it were, into a common stock, where every man may purchase whatever part of the produce of other men's talents he has occasion for. ${ }^{3}$

The marketplace forms a "common stock" in which people with their talents may come forth to better themselves not only by selling their goods but also by buying the goods of others. Smith rightly acknowledges the fact that the multiplicity of mankind creates the need for goods and services of others, and, therefore, something must be in a place that allows for the needs that cannot otherwise be sated by atomized individuals to be met. Hence, the marketplace and the act of trading is, much like morality, the meeting place between the individual and the larger society.

However, because trade connects both people and interest, a framework of what constitutes justice must be established for trade to serve its intended purpose: advancing the material well-being of all involved. Yet, how does this process happen? Can it occur without an appeal to a higher sense of morality? Smith, contrary to what some have suggested about the Adam Smith problem, believes that the economic system functions in a propitious manner because of a societal emphasis on justice.

Commerce and manufactures can seldom flourish long in any state which does not enjoy a regular administration of justice, in which the people do not feel themselves secure in the possession of their property, 
in which the faith of contracts is not supported by law, and in which the authority of the state is not supposed to be regularly employed in enforcing the payment of debts from all those who are able to pay. Commerce and manufactures, in short, can seldom flourish in any state in which there is not a certain degree of confidence in the justice of government. ${ }^{3}$

As one can see, Smith acknowledged the fact that trade cannot happen without a prevailing sense of justice. Contracts, private property rights, and the legal mandate that all debts must be prepaid are key to the creation of a functioning system of trade: all which tie into notions regarding justice. It is within the idea that trade is predicated upon a system of justice that a solution to the Adam Smith Problem starts to materialize.

Smith further expounds upon the necessity of justice as a framework for trade while discussing prudence.

In the middling and lower stations of life, the road to virtue is happily pretty much the same as the road to fortune, in most cases ... In all the middling and lower professions, it's nearly always possible to succeed through real and solid professional abilities combined with prudent, just, firm, and temperate conduct. And sometimes abilities will bring success even when the conduct is far from correct ... Such men can never be great enough to be above the law, and that inevitably overawes them into some sort of respect for the rules of justice or at least the more important of them ... ${ }^{4}$

Smith holds that there is an overlap between the so-called "road to virtue" and the "road to fortune." Hard work, the manifestation of the virtue of prudence, is essential for being successful in the marketplace and in being virtuous. Yet, Smith is careful to infuse the notion of the law within this linkage between the virtuous and economical. Behavior is maintained through obedience to the law and the judgmental eye of their neighbor. With the weight of both the law and the judgment of the community pertaining to moral conduct, the advancement of one's condition can take place. It is also important to note that Smith is referring to people of the middle and lower stations of life. This is in reference to those typically engaging in trade: merchants, farmers, brewers, bakers, etc.

In the courts of princes and in the drawing rooms of the great, success and advancement depend not on the es- teem of intelligent and well-informed equals but on the fanciful and foolish favor of ignorant, presumptuous, and proud superiors; and flattery and falsehood too often prevail over merit and abilities. ${ }^{4}$

This juxtaposition between the middle and lower stations against the upper stations is important. Members of the upper station, including lords, monarchs, et cetera, receive most of their wealth and standing from land and taxes. Therefore, justice not only acts as the predicate of trade, but it is also the direct result of the upper stations' prudence. This has important ramifications for the nature of the economy and society. Smith's emphasis on the fact that prudence, manifested through trade, necessitates a just society not only points to a solution of the Adam Smith Problem (being that a moral framework must exist for trade to be conducted efficaciously) but also to Smith's belief in the ever progressing nature of mankind through wealth proliferation predicated upon a system of justice.

\section{The Liberal Society of Smith}

Now that we see that there is an overlap between Adam Smith's moral and economic philosophies found within the concept of trade, one can now envisage what a Smithian system of trade with a moral base would look like. In "Adam Smith's Lost Legacy," Evansky promotes the notion that the culmination of Smith's work is the blueprint for the creation of a liberal society.

An ideal liberal society is ... one in which there are liberty and justice for all. Liberty offers freedom of movement and choice, and justice ensures the security that empowers individuals to take advantage of their liberties. With liberty and justice, the fluidity of movement of physical resources and of people and the free exchange of commodities through markets makes possible the greatest wealth for the nation. ${ }^{5}$

Smith's emphasis on the individual as both a moral and economic actor allows for Smith to be taken as both a moral and economic philosopher. The entire notion of a liberal society is predicated upon the individual's ability to act according to self-interest within the confines of a moral justice system. Once again, the idea of trade bridges self-interest and morality, as trade is mutually beneficial to both parties conducting the said transaction, so long as they are acting in accordance with a system of moral justice. This free and fair trade, in 
which the individual can trade with whomever they please and adhere to the basic guidelines codified within the justice system, allows for the general upward trajectory of mankind. This upward trajectory is leading mankind closer towards an ideal liberal society.

Before discussing the individual's place within Smith's liberal society teleology, let us highlight the defining trait of the individual: self-interest. For Smith, the individual is inextricably linked with the notion of self-interest; one might say that self-interest is the principal drive of mankind. "So although it may be true that every individual, in his own breast, naturally prefers himself [sic] to all mankind, he won't dare to look mankind in the face and declare that he acts according to this principle." 4 Smith does not shy away from the fact that everyone prefers herself over everyone - no matter how unseemly this might appear. By acknowledging the crass nature of mankind, Smith's moral and economic philosophy attempts to harness the self-interested nature of mankind. This is first manifested within the concept of trade.

In The Wealth of Nations, the idea of universal opulence is discussed as a positive by-product of individuals conducting trade with one another. At the core of the Smithian notion of trade was the division and specialization of labor.

It is the great multiplication of the productions of all the different arts, in consequence of the division of labor, which occasions, in a well-governed society, that universal opulence which extends itself to the lowest ranks of the people. Every workman has a great quantity of his own work to dispose of beyond what he himself has occasion for; and every other workman being exactly in the same situation, he is enabled to exchange a great number of his own goods for a great quantity, or, what comes to the same thing, for the price of a great quantity of theirs. He supplies them abundantly with what they have occasion for, and they accommodate him as amply with what he has occasion for, and a general plenty diffuses itself through all the different ranks of the society. ${ }^{3}$

This passage forms the crux of Smith's understanding of trade, acknowledged as based on self-interest, as a force for the progression of society. Smith argues that the division of labor is what drives trade. By assigning workers one task to master, other people can specialize in other functions, thus leading to a diversity and increase in production of goods. These goods are bought by other specialized workers, who in turn sell to other specialized workers. This allows for the market to grow and wealth to proliferate. Additionally, due to the ever-expanding nature of this system, the market is constantly becoming more diverse, which accommodates the needs and desires of more and more people. Wealth, therefore, is dispersed with greater and greater ease, for more people are specialized to produce the goods, and more and more people can afford goods. This system of trade benefits those with direct access to manufactured goods, skilled workers. These workers are safe in the knowledge that they will have access to other goods that they cannot produce. However, this system cannot contain itself. It must take place in a "well-governed society" and with "every other workman being in the same position" under the law. Both are produced through a system of justice regulated by moral principles. At the core of the legal system, much like the Smithian trade system, is the individual and his interaction with the system of greater morality.

At the core of the system of justice is an innate longing for each individual to be viewed in a positive light. For Evanksy, the individual, along with the propensity for being self-interested, is also concerned with the prevailing societal moral standards, or at least how he is viewed in the eyes of others through the lens of societal moral standards.

But we are also capable of weighing considerations of justice and beneficence as we choose our actions. Indeed, the character of a being in his story is determined by the balance of these sentiments (self-love, justice, and beneficence), for it is this balance that guides the actions of individuals as autonomous actors . . ${ }^{5}$

Evansky is also mirroring the Smithian notion that the lower and middle stations of life look upon the actions of others with moral principles in mind. This creates a system in which everyone is beholden to the larger moral standards of society, which allows for individuals to live their lives without fearing that someone will wrong them. Seeing that the lower and middle stations of life are the ones engaging in most of the trade, the societal moral standards are most acute within the realm of trade.

When the moral law of society is manifested properly, the system of justice expands liberty. Evansky reiterates Smith's belief that the proper instantiation of moral law leads to the expansion of liberty.

Smith believed that liberty can only be complete and thus the fruits of liberal society can only be fully realized where justice is based on a common willingness of 
citizens to voluntarily follow the dictates of civic ethics. In his view, to the degree that external Government enforcement of constructive behavior is necessary it not only reduces the fruits of liberal society, since productive resources must be used on enforcement, but it also reflects the tenuousness of that liberal experiment. A need for more Government reflects a lack of cohesiveness in a liberal order. ${ }^{5}$

As mentioned earlier in the essay, the "civic ethics" that Evansky is describing comes from the divine and is interacted with via the impartial spectator. Each member of that said society has the ability and the prerogative to obey civic ethics. Yet, Evansky takes Smith's moral philosophy to conclude that a liberal society is a moral one. Proof that society is liberal is reflected in the degree of enforcement of the societal moral standards. The more draconian the system of enforcement is, the less liberal it is. Enforcement of "civic ethics" is the duty of a society's legal system.

And men are naturally endowed with a desire for the welfare and preservation of society; but the Author of nature hasn't left it to men to use their reason to work out what kinds and levels of punishment are right for this purpose; rather, he has endowed men with an immediate and instinctive approval of just precisely the kind and level of punishment that is most proper to attain it. ${ }^{4}$

Commensurate with the divine origin of Smith's morality, the punishment for a violation of the law must also come from the faculties bestowed upon humankind by the Author of nature. Once again, this can be gleaned through the impartial spectator. As is also the case with the origin of morality, each society can utilize the impartial spectator in the doling out of punishment as they see fit; however, above all, this must be in accordance with the moral code.

Now that an inchoate model for a system of justice has been laid out, Smith argues that trade can flourish since one can confidently trade with others. This, in turn, allows society to advance.
[T]he path of humankind's evolution goes as follows: Progress from the rude state to the stage of hunting and gathering begins with the division of labor. The raison d'etre of the division of labor is the generation of surpluses that can be exchanged. But exchange requires rules-so even at this most rudimentary stage positive law emerges. The system of law becomes ever more complex as hunting and gathering gives way to pasturage, for the domestication of animals makes issues of ownership significantly more complex. ${ }^{5}$

Smith's belief in humanity's progress highlights the interconnection between his moral and economic philosophy. Wealth proliferation through free trade is predicated on a system of justice, the proper administration of which is ascertained through the impartial spectator, which ensures the stability of society. The reciprocal relationship between the economic growth and morality of Smith's belief in the progression of society not only renders the Adam Smith Problem solved, but it also highlights the culmination of Smith's philosophy: a liberal society. By analyzing Smith's entire corpus of work, one can see that the Adam Smith Problem is not so much a problem of consistency of thought but rather a challenge to discern what Smith is truly getting at in his musings: a liberal society.

\section{References:}

Otteson, James R. "The Recurring “Adam Smith Problem"." History of Philosophy Quarterly 17, no. 1 (2000): 69

Otteson, James R. Adam Smith's Marketplace of Life. Cambridge: Cambridge University Press, 2002

Smith, Adam. Adam Smith \& The Wealth of Nations. Liberty Fund.

Smith, Adam. The Theory of Moral Sentiments. Edited by Jonathan Bennett, 2017.

Evensky, Jerry. "Adam Smith's Lost Legacy." Southern Economic Journal 67, no. 3 (2001): 506 